LA W RENCE LIVERMORE N A TIO NAL LABORATORY
An optimized bioink for three-dimensional printing of endothelial cells into a vascular-like structure.

K. M. Dimengo

August 14, 2013 
This document was prepared as an account of work sponsored by an agency of the United States government. Neither the United States government nor Lawrence Livermore National Security, LLC, nor any of their employees makes any warranty, expressed or implied, or assumes any legal liability or responsibility for the accuracy, completeness, or usefulness of any information, apparatus, product, or process disclosed, or represents that its use would not infringe privately owned rights. Reference herein to any specific commercial product, process, or service by trade name, trademark, manufacturer, or otherwise does not necessarily constitute or imply its endorsement, recommendation, or favoring by the United States government or Lawrence Livermore National Security, LLC. The views and opinions of authors expressed herein do not necessarily state or reflect those of the United States government or Lawrence Livermore National Security, LLC, and shall not be used for advertising or product endorsement purposes.

This work performed under the auspices of the U.S. Department of Energy by Lawrence Livermore National Laboratory under Contract DE-AC52-07NA27344. 


\section{An Optimized BioInk for three-dimensional Printing of Endothelial Cells into a Vascular-Like Structure}

\section{BACKGROUND}

Traditionally cells have been cultured on two-dimensional plates. However, twodimensional cell culturing has many known limitations. For instance, cell morphology differs in a monolayer, and epigenetic expression of genes and proteins can vary dramatically due to the constraints of cells being in a single plane (Tibbitt, 656). Nor do cells in a monolayer grow, migrate, or form tissue in a natural manner or as cancer metastasizes. This is largely due to the inability of cells to send and receive signals the way they actually do in the human body (Han, 4251). This often limits the utility of in vitro studies done in only two dimensions, even for drug testing and toxicity studies and significantly limits tissue engineering. Additionally threedimensional cell culturing could lead to more accurate representational studies in vitro and even tissue engineering to relieve intense pressure for on medical needs for organ replacement (Nikkah, 9009). Recent efforts to develop three-dimensional cell cultures and tissues have made significant advances. A variety of methods have been used to generate thicker tissues, including scaffolds (Han, 4251), microfluidics (Shin, 1247), and additive manufacturing (Marga).
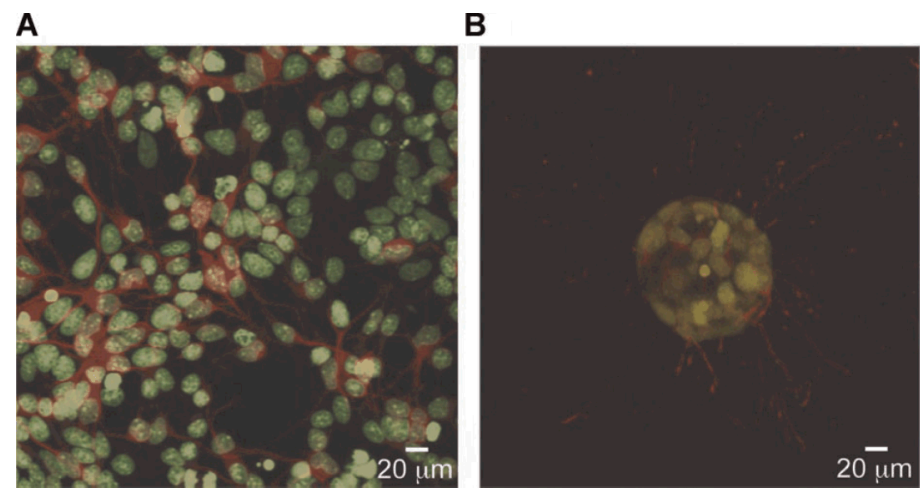

Figure 1: Differences in morphologies of cells grown in monolayer (left) versus threedimensional culturing (right) (Tibbitt, 656). 
A significant limitation of current three-dimensional cell culturing and tissue engineering is that thicker tissues are extremely difficult to maintain because of the lack of vasculature (Novosel). Although some tissue grafts can be created layer by layer in vivo, such as certain cardiac tissue (Jakab, 4), no current method exists to go from in vitro tissue engineering to an in vivo implantation (Id.), let alone for use in model studies for most organs. For this reason, successful tissue engineering has been general limited to tissues that do not require significant vascularization such as skin and cartilage (Nikkhah, 9009). In vivo, each cell is no more than 200 $\mu \mathrm{m}$ from a capillary and often far less (Novosel, 302). Capillaries and the vascular network as a whole provide two essential functions: (1) they perfuse the tissue and cells with nutrients and oxygen, and (2) they remove waste products and carbon dioxide. Furthermore, the addition of growth media to two-dimensional cell cultures does not replicate the natural perfusion that occurs via vasculature, which requires perfusion that is more homogenous and stable than occurs on plated cells $(\mathrm{Wu}, 232)$.

A number of techniques have been attempted to create vascularized tissue, such as immobilizing angiogenic growth factors, directly distributing vascular tissue in the overall engineered tissue, and making micro- and nano-scale vasculature either artificially or through manipulating hydrogel patterning (Nikkhah 9010). Additive manufacturing intends to engineer tissues without the use of exogenous scaffolds (Marga, 2). Many techniques from other areas of manufacturing and production techniques have been used, such as inkjet printing (Khatiwala, 2), laser-guided engineering (Nahmias, 135), photolithography (Nikkhah, 9017), microfluidic platforms (Chung, 270), and pressure extrusion bioprinting (Marga, 3). 


\section{Vasculogenesis and Angiogenesis}

The human vascular network is composed of three major cell types: endothelial cells, vascular smooth muscle, and fibroblasts. Some organ's endothelial tissues have other cells; for example the blood brain barrier includes astrocytes (Ballabh). Endothelial cells encapsulate the vessel lumen through which oxygen and nutrients travel to cells and diffuse into them. Likewise cellular waste and carbon dioxide exit the cells through the lumen.

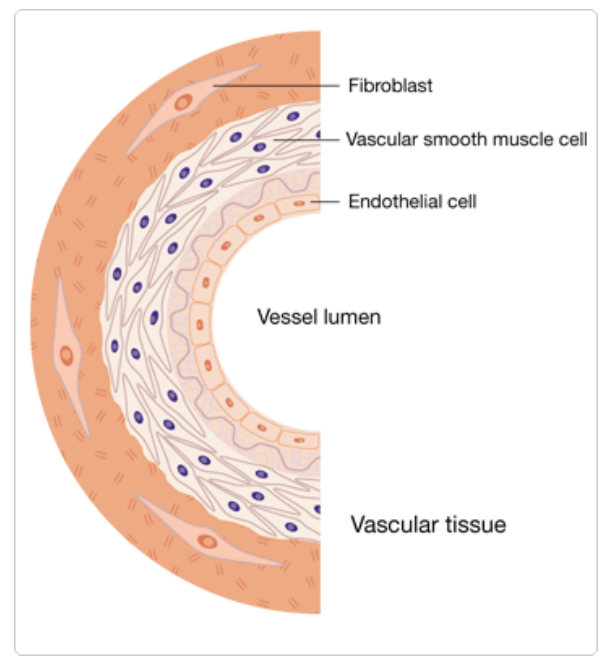

Figure 2: Diagram of typical vascular tissue in humans.

(Invitrogen.com)

Vasculogenesis is the process by which undifferentiated endothelial cells (i.e., endothelial progenitor cells) become capillaries. Angiogenesis is the process by which capillaries form from blood vessels that already exist. A vast number of biochemical signals play a role in regulating these processes from numerous growth factors, adhesion proteins, cell-cell junctions, and inhibitors (Novosel, 303). Additionally, various biophysical signals assist in the proliferation of blood vessels. In vivo, the degeneration of vascular tissue leads to tissue death, whereas the overproliferation of vascular tissue is critical to tumor formation. Thus the formation of vasculature artificially requires careful manipulation of these signals and is complicated by the cross-talk among these signals. 
Growth factors lead to a cascade of biochemical reactions to cause cells to migrate and proliferate to form vessels. Important angiogenesis growth factors and cytokines include: vascular endothelial growth factor (VEGF), hepatocyte growth factor (HGF), basic fibroblast growth factor (BFGF), platelet-derived growth factor (PDGF), and transforming growth factor (TGF- $\beta$ ) among many others (Novosel, 304). When attempting to artificially reproduce vasculature tissue, these can be added separately to growth medium, to hydrogels or threedimensional scaffolds, or up-regulated through transfection of the cells. Angiopoieins are another type of protein that helps to stabilize vasculature (Lamalice, 788).

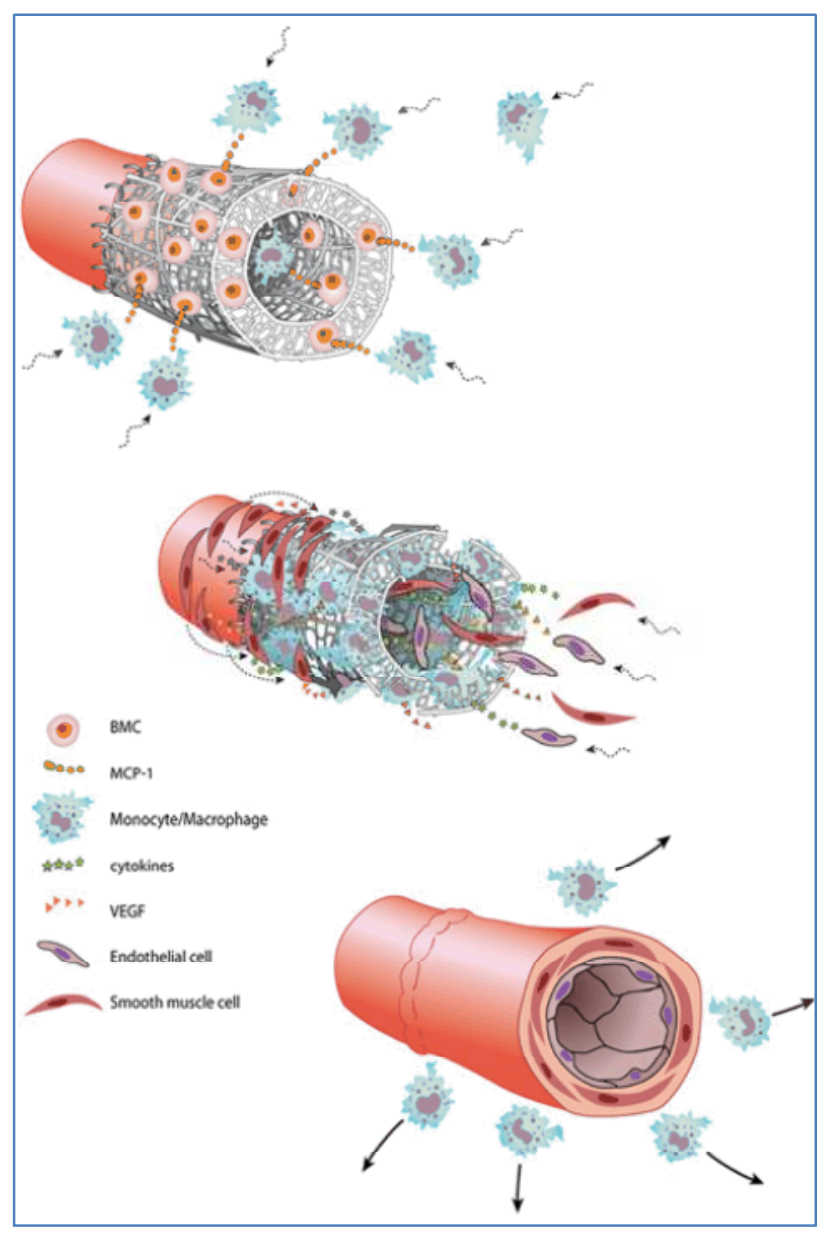

Figure 3: Vasculogenesis model process with growth factors. Vessels are formed by recruiting VEGF; $M C P-1$, a chemokine that attracts monocytes; and various other cells and molecules related to the immune system (Roh, 4673). 
Angiogenesis is influenced similarly and also by chemical gradients of surrounding the extracellular matrix ("ECM") proteins, break down the ECM during angiogenesis to provide more room for endothelial cells to proliferate (Tibbitt, 658). Likewise, the ECM and endothelial cells are able to adhere to each other by connecting focal adhesions to actin. The biophysical signals for angiogenesis include the constant shear stress that is applied to endothelial cells by constant fluid movement (Lamalice, 783). Shear stress helps to separate cell-cell connections, activates the actin pathway, and helps direct the cell migration (Lamalice, 790-1).

To form into vessels in vivo, endothelial cells connect to the basal surface of the basement membrane, a thin, specialized complex like the ECM, discussed in more detail below (Arnaoutova, 267). The basement membrane forms a sleeve around the endothelial cells to help the cells maintain the classic tubular form of blood vessels (Id.). This occurs as cells sort by selfassembly to form a lumen as the cells differentiate, become polarized, and express adhesion molecules on their surface (Jakab, 5).

\section{Extra Cellular Matrix and the Basement Membrane}

The ECM is a combination of a variety of proteins, polysaccharides, and water. The ECM, while unique to each tissue, serves as a scaffold for cellular growth and stability, and importantly, produces a host of biochemical and biophysical signals to surrounding cells (Franz, 4195). The ECM affects the elasticity and strength of the tissue and binds growth factors to receptors on cell surfaces to direct cell growth, proliferation, morphology, migration, and differentiation. The ECM is primarily made from two types of macromolecules. Proteoglycans, such as perlecan, biglycan, decorin, and lumican, form a hydrating gel. This assists in buffering and growth factor binding. Fibrous proteins, such as collagen, laminin, fibronectin, and elastin, provide more structure to the ECM, serve as a scaffold, and assist with cell adhesion and 
migration. The ECM also contains a large number of other smaller proteins that provide signaling to surrounding cells. For instance, integrin helps cells to adhere to proteins in the ECM and to each other (Franz, 4197). Metalloproteinases, on the other hand, break down the ECM (Tibbitt, 658).

Of the fibrous proteins mentioned above, collagen is the most abundant. At least 28 forms of collagen have been isolated in humans (Franz, 4197). Type I collagen is a triple helix and is the most commonly found type of collagen, and promotes sufficient structural support (Fiejdasz, 2). Other collagen types, such as Type IV, is more important to cell adhesion and migration, particularly in the basement membrane (Arnaoutova, 268).

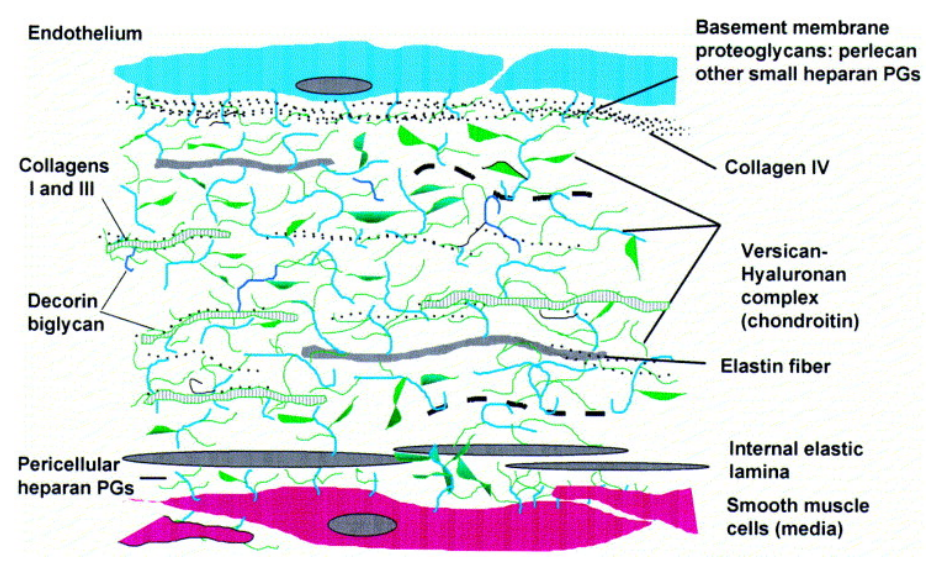

Figure 4: Diagram of typical ECM (Camejoa, 207)

In addition to providing structure, the ECM also releases growth factors and contains focal adhesions necessary for angiogenesis (Lamalice 788). In particular, actin, which enables endothelial cells to move, is anchored to ECM proteins. The manipulation of growth factors in the ECM and other molecules has been shown to improve tissue engineering. For example, VEGF and PDGF can be tethered to ECM proteins in different layers to enhance the growth of endothelial cells in vitro (Han, 7303). 
A second important structural element is the basement membrane, which is on the apical side of the ECM. Like the ECM, the basement membrane is tissue-specific, but includes typically laminins, collagen IV, and nidogens/entactins. There are also growth factors among other structural and signaling proteins (Arnaoutova, 268). Laminins are the primary protein of the basement membrane, both structurally and for adhesion, migration, and differentiation of cells (Id.). The basement membrane is also very dynamic to help heal tissues when harmed by trauma or disease (Id.).

\section{Three-Dimensional Cell Culturing}

Three-dimensional cell culturing has been developed from a variety of synthetic and natural materials, typically polysaccharides or proteins (Fiejdasz, 8). Synthetic materials are often used to create three-dimensional scaffolds that mimic natural ECM, a difficult process requiring a balance of many factors including: permitting ECM proteins the ability to move in the scaffold - porosity; inclusion of other proteins, such as growth factors - tethering; and degradability (Tibbitt, 358-9). Moreover, these attributes need to be adjusted over time to permit cell growth (Id.). On a micro-level, a three-dimensional culture must control for a variety of factors including adhesive and migratory attributes, stiffness, and solubility for nutrient flow (Baker, 4).

These materials are often grouped as hydrogels, which are typically at least $99 \%$ water. Many of these have been shown to be successful at certain tissue engineering, such as skin, bone, and cartilage, but have various limitations. Some, for instance, many materials must be degraded to allow the cells to proliferate properly and generally must have cellular signals, such as growth factors, added separately ${ }^{1}$ (Marga, 2).

\footnotetext{
${ }^{1}$ An exception to this is BD Bioscience's Matrigel ${ }^{\mathrm{TM}}$, which is formulated to include several major growth factors, discussed below.
} 
Some naturally derived materials from humans include fibrinogen and thrombin, which forms fibrin (Zhao), collagen, fibronectin, collagen, hyaluronic acid, and laminin. Commercially developed products that contain multiple proteins found naturally in the ECM or the basement membrane include BD Bioscience's Matrigel ${ }^{\mathrm{TM}}$ and Glycosan's Extracel®. Sodium alginate, agarose, gelatin, and chitosan are examples of natural materials that are derived from non-human sources. To improve the accuracy of cell and tissue culturing, three-dimensional scaffolds have been synthetically. The artificial materials typically used include organic polymers, such as polyethylene glycol and agarose. Materials that are artificial must be tested for their biocompatibility for with seeded cells and must generally be able to be degraded for the cells to eventually become tissue.

Some hydrogels and three-dimensional scaffolds require significant manipulation, such as stiffening by exposure to UV light (Guvendiren). While this often gives very strong scaffolds, the exposure to UV light can have significant negative impacts on cell viability and morphology. For example, agarose has been used to grow retina stem and progenitor cells to form endothelial tissue in a highly regular and well-controlled scaffold (Aizawa, 5199).

With such an abundance of materials, many factors influence which type of hydrogel may be best for a particular type of cell. Stiffness is frequently cited as a primary determiner of cell adhesion and spreading with higher stiffness leading to more cell adhesion (Chen, 247; Chung, 273). However, stiffness is not always the determining factor, for example by immobilizing other molecules on the hydrogel, such as photo-cross linked HA-heparin hydrogels modified with CD34-Ab (Camci-Unal, 343) to help adhesion. Synthetic materials typically require degradation of the scaffold, mechanical "mismatches", and, if used for human transplantation, immune/inflammation problems (Williams, 2943). Hence, natural materials are favorably 
utilized, though also with limits in reproducibility, low throughputs, limits to scalability, and precise positioning of cells (Norotte). Collagen hydrogels can be formed by high temperatures, generally $37^{\circ} \mathrm{C}$ or higher, and/or chemical cross-linking (Id.) Collagen stiffness can be adjusted by changing the $\mathrm{pH}$ before polymerizing the gel (Chung 274).

Matrige $\mathrm{T}^{\mathrm{TM}}$ is composed of a blend of natural proteins mimics the basement membrane but is also very similar to the proteins in the extracellular matrix. Matrigel ${ }^{\mathrm{TM}}$ is derived from Engelbreth-Holm-Swarm mouse carcinoma (Franz, 4198). This hydrogel contains collagen, laminin, and entactin, as well as the growth factors: bFGF, EGF, IGF-1, PDGF, NGF, and TGF$\beta$. Matrige ${ }^{\mathrm{TM}}$ has been shown to effectively grow a variety of cells, including neurons and vascular endothelial cells. However it has drawbacks for reproducible testing due to variability of the porosity of the material batch to batch (Aizawa, 5204). Moreover, the protein concentrations of the Matrigel ${ }^{\mathrm{TM}}$ vary from batch-to-batch limiting the reproducibility of results if they are dependent on the exact formulation of the Matrigel ${ }^{\mathrm{TM}}$ (www.bdbiosciences.com).

Another naturally-derived hydrogel for three-dimensional cell culture is sodium alginate, which is an anionic polymer with good biocompatibility, low toxicity, and the ability to have different kinds of crosslinking and tethering of other proteins (Duan, 1262). It can be used in many applications because its viscosity can be adjusted by increasing the concentration of the alginate and increasing the temperature (Id.). Alginate has been used in a variety of hydrogels, and also with other materials. For example, alginate has been used with extrusion printing to grow aortic valves in combination with gelatin (Duan, 1256). In this method, two types of cells were printed separately onto a hydrogel made of alginate/gelatin in multiple patterns (Id., 1261). Complex procedures have been applied to create unique spiral scaffolds, for instance (Kouwer, $651)$. 


\section{Bioprinting}

The principle of tissue engineering relies on several major processes, including cell-tocell interactions, signals in the extra cellular matrix, and self-assembly (Jakab, 1). Bioprinting has been a major focus for tissue engineering because it potentially offers a way to more precisely develop multicellular systems (Ozbolat, 691). Additionally, bioprinting could enable the use of higher cell density to start with, tightly controlled deposition of ECM and other molecules, and specific placement and patterning of cells (Jakab, 5). The major way to accomplish bioprinting is by creating "bioinks" that are typically printed onto a biocompatible, such as a natural or synthetic hydrogel or ECM protein, substance layer by layer (Mironov 2055). Often the bioinks used are made into aggregates shaped as spheres or cylinders (Jakab, 8). Three common methods are to use modified inkjet printers, laser-directed methods, and mechanical extrusion (Ozbolat, 691).

Inkjet-based bioprinting enables the simultaneous deposition of multiple substances, e.g., cells, drugs, and growth factors, simultaneously using modified commercially available printers (Cui, 6221). Vascular tissue has been printed in this manner utilizing human microvascular endothelial cells mixed in a bioink of thrombin and calcium ions (Id.). The cells/thrombin bioink was printed within a fibrin channel onto fibrogin (Id.). After 21 days, the cells adhered into a micron-sized fibrin channel (Id.). Laser-directed printing is achieved by exciting cells in order to direct them via a bubble which is formed by the laser pulse (Ozbolat, 692). Very precise patterning can be done using this method; by depositing a hydrogel on top of the cells, a threedimensional construct is made. However, only very small constructs - a couple of millimeterscan be made by laser placement (Duan, 1256). 
Another method involves creating multicellular spheroids around agarose rods to create vessels with differing thickness, diameter, and branching that is deposited on collagen (Norotte; Jakab). These were made into cylindrical units that fused to create fused branches via a twoheaded bioprinter. However, this model had limitations as the tissue was slightly thicker than could easily be perfused - about $900 \mu \mathrm{m}$, the removal of the agarose rods, and the precise placement of different types of cells. In a recent study, heart valves were printed by encapsulating two types of cells in a gelatin-alginate hydrogel using a dual-head printer (Duan).

Extrusion printing is based on using air pressure to dispense a cylinder of biomaterial typically without requiring a scaffold (Jakab 9). This provides greater structural stability for the final structure, though at the expense of applying greater shear force to the cells, potentially causing high cell loss (Ozbolat, 693). A variety of mechanical aspects of extrusion bioprinting can be optimized to increase cell viability, including: pressure strength, nozzle diameter, concentration of the bioink, and density of the cells loaded (Id.). Biomaterials must be at the right viscosity to balance between the low viscosity needed to extrude the substance versus the problem of clogging the nozzle (Id.).
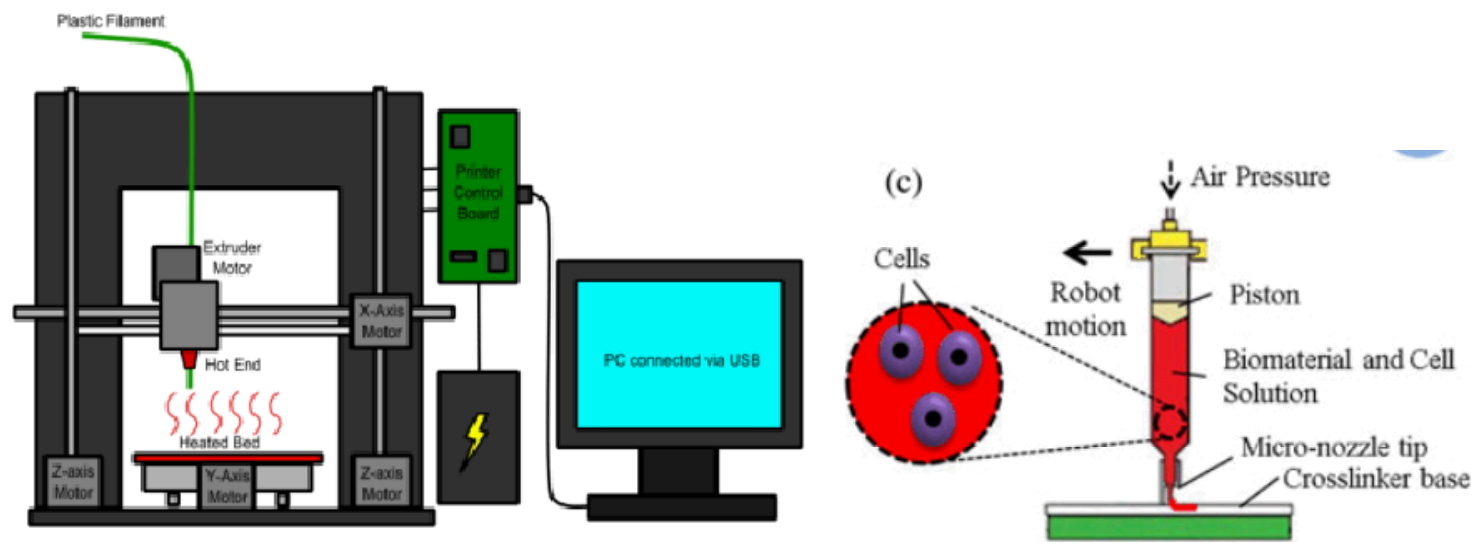

Figure 5: Diagram of typical extrusion-based plastic three-dimensional printer (left); Gronkbot 3D Printing); detail of uniaxial extrusion method (right; Ozbolat, 692). 
Several types of bioprinters have been used, including envisionTEC GmbH's threedimensional Bioplotter, Organovo's Novogen MMX Bioprinter, and the University of Iowa's Multi-Arm Bioprinter (Ozbolat, 696). Commercially available machines can costs upwards of $\$ 200,000$ (Id.).

\section{Micro-Chip Devices}

The technique of bioprinting may have applications beyond three-dimensional cell culturing, such as in experiments that require very precise placement of biomaterials. Researchers have worked to create organs on microchips that combine cell biology with microtechnology (Baker, 661). These platforms attempt to recreate realistic organ systems on silicon or plastic wafers (Id.). Ideally, this would enable the testing of drugs and toxins on a complex model prior to or even replacing animal models (Id., 664). While microfluidics are used in some research (Esch, 58), researchers at the Lawrence Livermore National Laboratory are experimenting with microelectrode arrays to create a brain on a chip using neurons on silicon wafers (Fox, 3).

Microchips are being designed for drug assays for brain tissue from a silicon wafer with sixteen micro-electrodes arranged in a four by four array. The electrodes are approximately 30 to $50 \mu \mathrm{m}$ in diameter with a 200 to $250 \mu \mathrm{m}$ pitch depending on the model. Ideally, neurons would be attached directly over each micro-electrode so that the activity and response of each neuron would be tested individually. It is important for the neurons to be extremely close to the electrodes to ensure that even weak activity signals are picked up by the electrophysiology equipment. This requires extremely precise placement that has yet to be achieved by manual spotting. 


\section{MATERIALS AND METHODS}

\section{Bioprinter}

A MakerBot Replicator Desktop three-dimensional Printer (MakerBot; Brooklyn, NY) was used to print all bio materials. The Replicator printing was programmed using MakerWare (MakerBot, Brooklyn, NY) which utilizes a .gcode format. The Replicator was augmented by replacing the apparatus designed to print plastic with a precision fluid dispensing system (Nordson; Westlake, $\mathrm{OH}$ ) which extruded the bio materials by using air pressure. Associated 10cc syringes, equalizers, and tubing (Nordson; Westlake, $\mathrm{OH}$ ) were used. Plastic and metal/plastic pipet tips were purchased from Nordson. The $30 \mu \mathrm{m}$ glass pipet tips were purchased from World Precision Instruments (Sarastoa, FL).

\section{Hydrogels.}

BD Matrigel ${ }^{\mathrm{TM}}$ Matrix was purchased from BD Biosciences (Franklin Lakes, NJ). The Matrigel $^{\mathrm{TM}}$ was reconstituted by thawing on ice. Prepared and aliquoted Matrigel ${ }^{\mathrm{TM}}$ was stored in a $-20^{\circ} \mathrm{C}$ freezer. To dilute the Matrigel ${ }^{\mathrm{TM}}$ with growth media, the Matrigel ${ }^{\mathrm{TM}}$ was thawed in a 4 ${ }^{\circ} \mathrm{C}$ refrigerator until it became liquid again. For dilute Matrigel ${ }^{\mathrm{TM}}$ experiments, endothelial cell growth media (PromoCell; Heidelberg, Germany) was added and then gently pipetted up and down to mix the two substances.

BD Puramatrix ${ }^{\text {TM }}$ Peptide Hydrogel was purchased from BD Biosciences (Franklin Lakes, NJ). Undiluted Puramatrix ${ }^{\mathrm{TM}}$ was prepare by vortexing and then, after being pipetted into a syringe, was covered with twice the volume of Puramatrix ${ }^{\mathrm{TM}}$ with endothelial growth media. The Puramatrix ${ }^{\mathrm{TM}}$ was incubated for 30 minutes at $37^{\circ} \mathrm{C}$. The media was changed twice to equilibrate the $\mathrm{pH}$, as according to the manufacturer instructions. 
Agarose was purchased from Sigma Aldrich (St. Louis, MO). This was dissolved with phosphate buffered saline, $\mathrm{pH} 7.4$, and heated to $120^{\circ} \mathrm{C}$, to the desired concentration of agarose. The percentage of agarose was varied on a weight to volume basis to $1.0 \%, 1.5 \%$, and $2.0 \%$. A total volume of $2 \mathrm{~mL}$ was prepared for each sample. While still liquid, the agarose was cooled slightly and then injected into a syringe and allowed to gel before printing. Time of gelation depended upon the concentration of the agarose, but was approximately 15 to 20 minutes.

Extracel® (Glycosan; Alameda, CA) was purchased commercially and is made of three components, Glycosil ${ }^{\circledR}$, a thiol-modified hyaluronan, and Gelin-S ${ }$, a thiol-modified gelatin, were reconstituted with deionized water provided by the manufacturer, with $5.0 \mathrm{~mL}$ added to the proteins. After these were thoroughly dissolved for 30 minutes at $37{ }^{\circ} \mathrm{C}$ with gentle vortexing, they mixed by pipetting. The Extracel ${ }^{\circledR}$ cross linker, which is polyethylene glycol diacrylate, was also dissolved in $2.5 \mathrm{~mL}$ of deionized water then immediately mixed with the other combined components at a 1:4 ratio of cross-linker to hydrogel components. Gelation occurred chemically within 20 minutes of mixing.

Two collagen solutions were used: PureCol® EZ Gel, Bovine Collagen Solution, Type I in DMEM/F-12 Medium, $5 \mathrm{mg} / \mathrm{ml}(0.5 \%)$ and VitroCol ${ }^{\circledR}$ Human Collagen Solution, Type I, 3 mg/mL (Advanced BioMatrix, San Diego, CA). PureCol ${ }^{\circledR}$ was gelled by incubation at $37{ }^{\circ} \mathrm{C}$ for 90 minutes. VitroCol® was first diluted at an 8 to 1 ratio with $10 \mathrm{X}$ PBS. The $\mathrm{pH}$ was adjusted using $0.1 \mathrm{M} \mathrm{NaOH}$ of approximately 7.6, and the sterile water added to bring the total ratio of collagen to $10 \mathrm{X}$ PBS to water to $8: 1: 1$. The collagen was gelled by incubation at $37{ }^{\circ} \mathrm{C}$ for 120 minutes.

Sodium alginate (Sigma Aldrich; St. Louis, MO) was dissolved in sterile water in a $37^{\circ} \mathrm{C}$ incubator overnight while being shaken at $120 \mathrm{rpm}$; solutions with concentrations $(\mathrm{w} / \mathrm{v})$ of $1 \%$, 
$2 \%$, and $4 \%$ were made. A stock of (w/v) $4 \%$ calcium chloride at $>93 \%$ purity (Sigma Aldrich;

St. Louis, MO) was dissolved in sterile water at room temperature.

Poly-D-lysine (Sigma Aldrich; St. Louis, MO) was dissolved in a borate buffer $(\sim \mathrm{pH} 8)$ at $0.1 \mathrm{mg} / \mathrm{mL}$. After plating onto the culture surface, the PDL was incubated for one hour at room temperature, rinsed with water, and allowed to dry overnight. The following day, the PDL was coated and incubated for 30 minutes, rinsed again with water, and dried for one hour.

\section{Imaging}

The printed biomaterials were viewed using a handheld, digital microscope (Dino-Lite; New Taipei City, Taiwan) at approximately 20X magnification. Photographs and video were taken with the Dino-Lite microscope via the Dino-Capture software (Dino-Lite; New Taipei City, Taiwan). Images of HUVECs and neurons were obtained with a Leica DMI6000 microscope (Leica Microsystems; Wetzlar, Germany) and imaged with a Retiga EXi Fast 1394 (QImaging; Surrey, BC, Canada).

\section{Cell culture}

Human umbilical vein endothelial cells (HUVECs) were cultured in supplemented endothelial growth medium (PromoCell; Heidelberg, Germany) at $37^{\circ} \mathrm{C}, 5 \% \mathrm{CO}_{2}$. Medium was

changed every three days, and cells were harvested at 80\% confluency using HEPES and trypsin (PromoCell; Heidelberg, Germany) treatment. Cell density was measured with a hemocytometer (Olympus BX61; Tokyo, Japan) by mixing with equal parts of trypan blue (Sigma Aldrich; St. Louis, MO).

Neurons were obtained from postnatal rats (about 3-4 weeks old). The brain tissue was removed surgically and digested in Collagenase-IV and cultured in media containing DMEM/F12, FBS, NGF, G-21, and Pen/Strep. The neurons were resuspended in 400uL of the 
media. For manual spotting, the cells were plated in $4 \mu \mathrm{L}$ drops over the electrode arrays. For bioprinting, $20 \mu \mathrm{L}$ of re-suspended cells was diluted into $1 \mathrm{~mL}$ of growth media.

\section{RESULTS}

Several materials were used to create sample bioinks: BD Matrigel $^{\mathrm{TM}}$, BD Puramatrix ${ }^{\mathrm{TM}}$, Extracel ${ }^{\circledR}$, agarose, collagen, and sodium alginate. In addition, HUVECs and neurons were printed in several materials and with different methods. Each were tested multiple times using a Makerbot Replicator three-dimensional printer. The Replicator was adapted to extrude the biomaterials at a given pressure from $0.1 \mathrm{psi}$ to $60.0 \mathrm{psi}$, or with no pressure at all. Two computer scripts were used to test the precision of printing. One created four by four arrays of small droplets and another single drop/column printing. Biomaterials were also printed by manual extrusion by pulsing at a set pressure.

\section{Growth Media Bioprinting}

Testing of the Replicator system began by printing endothelial growth media on a standard petri dish. Growth media contains fetal calf serum, EC growth supplement, epidermal growth factor, basic fibroblast growth factor, insulin-like growth factor, vascular endothelial growth factor, ascorbic acid, heparin, and hydrocortisone, but at such levels that the viscosity is nearly identical to water. The Replicator was able to precisely print growth media into single drops with a diameter of approximately $150 \mu \mathrm{m}$ using a $50 \mu \mathrm{m}$ glass tip. Similarly, using a 100 $\mu \mathrm{m}$ metal tip, drops were approximately $330 \mu \mathrm{m}$ in diameter. Spreading of the growth media printing was consistently about three times the tip size. However, the drops were very precise and replicable in both size and in pitch when printed in an array. Low pressure of only $0.1 \mathrm{psi}$ was needed to extrude these small droplets. The primary disadvantage of these tests was that the 
droplets dried extremely quickly severely limiting cell viability, as well as the structural integrity of the materials.

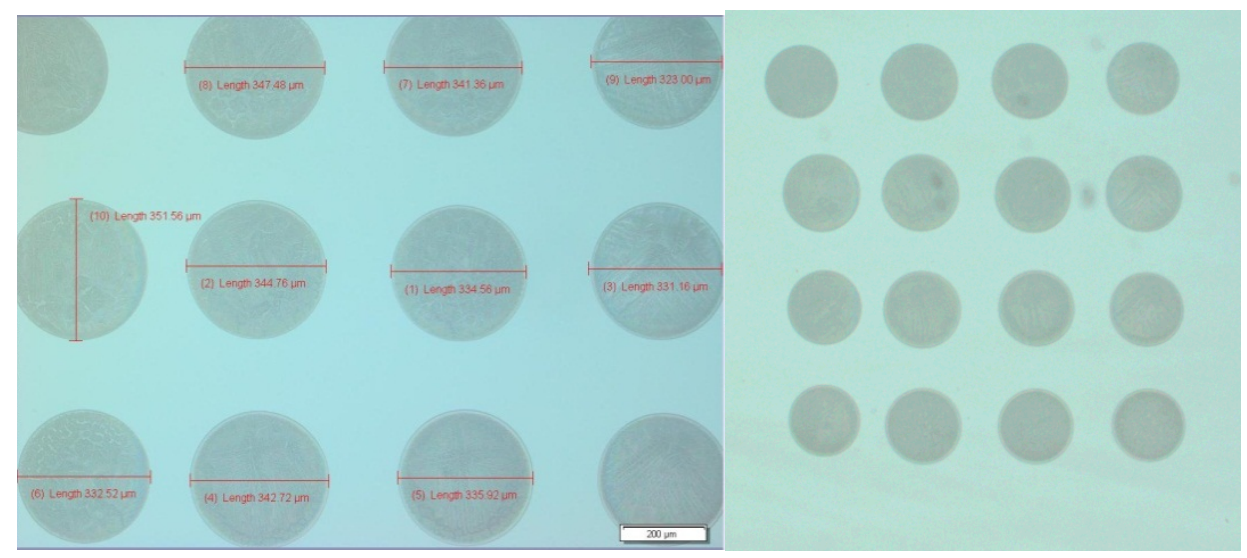

Figure 6: Growth media printed in a 4x4 array with $100 \mu$ m tip (left); wide view (right).

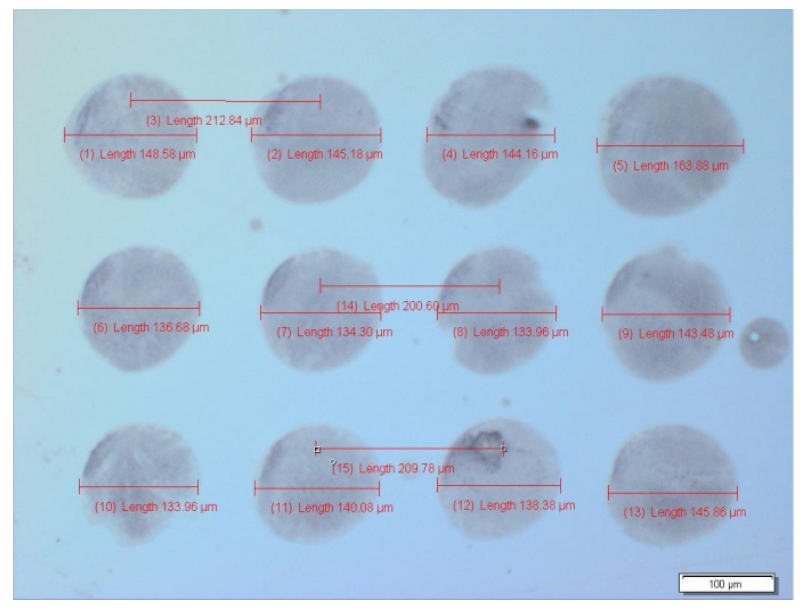

Figure 7: Growth media printed in a $4 \times 4$ array with $50 \mu \mathrm{m}$ tip.

To test the precision of the bioprinter on different surfaces, an array of growth media was printed onto a microelectrode device made with glass and coated with polyimide. As on the petri dish, the growth media was precisely deposited using a $100 \mu \mathrm{m}$ tip at a $200 \mu \mathrm{m}$ pitch. However, there was visibly more spreading of the drops in the first row of the array. This may have been due to the different surface of the device. Additionally, the low magnification power of the microscope did not allow for perfect alignment of the nozzle with the array. Because the drops 
were not precisely on the array, we also tested printing one large drop that covered the entire array without covering the reference electrode.

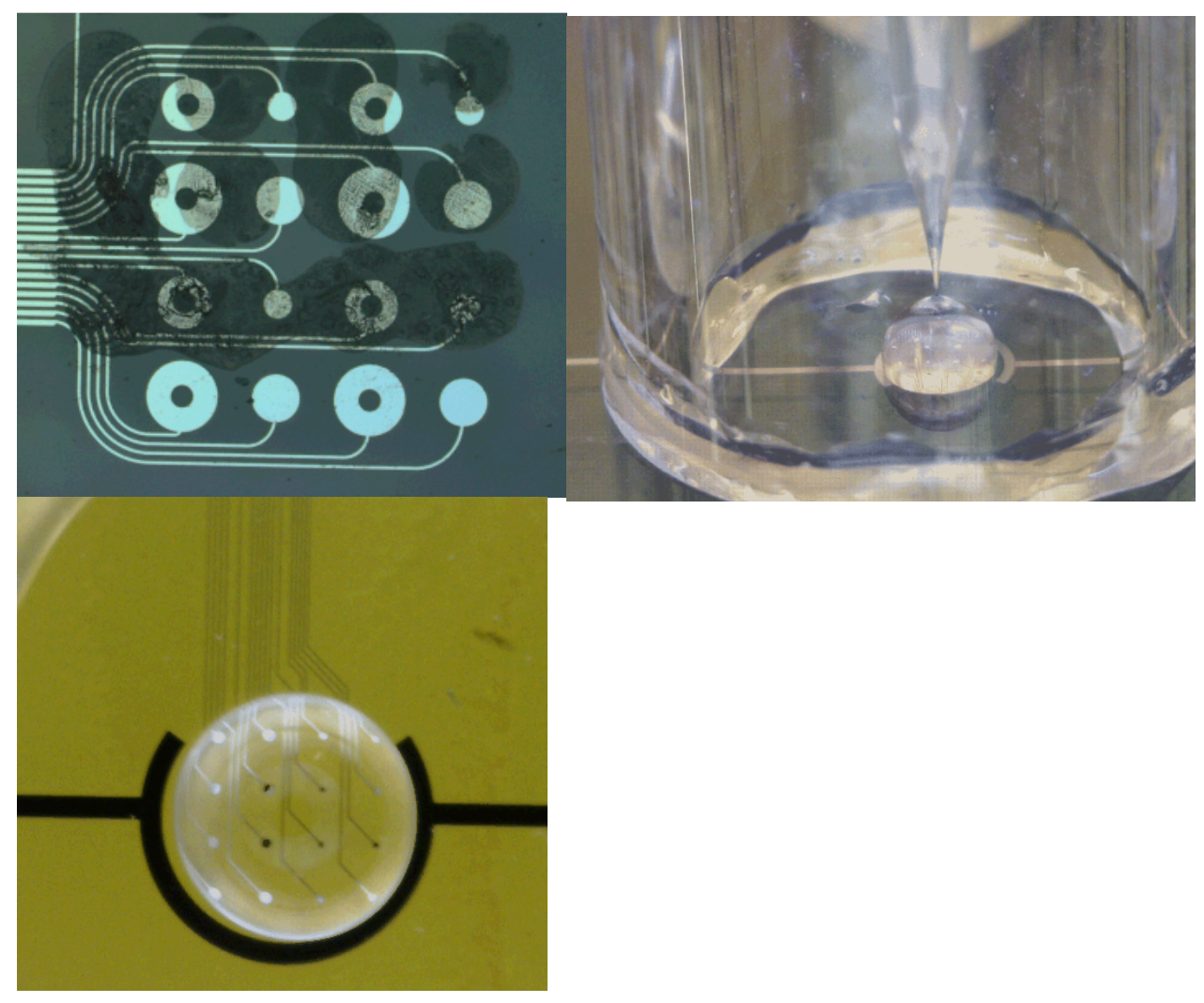

Figure 8: Growth media printed on an electrode array (left); large drop in well (right); large drop from above covering array (bottom).

\section{Extracel ${ }^{\circledR}$}

To test whether the Replicator could print lower viscosity biomaterials, Extracel® was printed. Extracel ${ }^{\circledR}$ is a commercially available hyaluronan-based hydrogel that is modified with thiol groups. Unlike some other hydrogels, Extracel® forms into a gel at room temperature and without having to adjust its $\mathrm{pH}$. Extracel® forms a nearly transparent hydrogel, which is useful for observing cells. Extracel ${ }^{\circledR}$ was prepared in a standard 1\% dilution. Although it appeared to be much stiffer than growth media when gelled, the Extracel ${ }^{\circledR}$ became looser and jelly-like when printed, and thus not viable to create a fully three-dimensional structural tissue. 


\section{Matrigel ${ }^{\mathrm{TM}}$}

Matrigel $^{\mathrm{TM}}$ was tested at three concentrations: undiluted, 10\% Matrigel $^{\mathrm{TM}}$ in growth media, and 20\% Matrigel ${ }^{\mathrm{TM}}$ in growth media. Like Extracel ${ }^{\circledR}$, Matrigel ${ }^{\mathrm{TM}}$ is a lower viscosity liquid that forms a three-dimensional hydrogel at room temperature. A $100 \mu \mathrm{m}$ tip was used for printing given the lower viscosity. Although it initially maintains a stiff appearance, when printed, Matrigel $^{\mathrm{TM}}$ becomes jelly-like and the edges become a liquid. Without sufficient structure, Matrigel $^{\mathrm{TM}}$ was too soft to create a stand-alone bioink for vasculature. Matrigel ${ }^{\mathrm{TM}}$ was also tested with growth media as a way to see if cells could be dispensed in growth media onto an electrode to avoid drying out small drops or washing the cells away. The higher concentration gelled more stiffly, though both concentrations when printed had viscosity of the mixture was similar to that of growth media alone and spread about three times the size of the tip when dispensed. Interestingly, however, the 20\% Matrigel $^{\mathrm{TM}}$ mixture clogged the nozzle after less than 10 minutes and did not extrude when the dispensing pressure was less than 10.0 psi, indicating that despite its appearance, the 20\% Matrigel $^{\mathrm{TM}}$ was sticking to the sides of the syringe.

\section{PuraMatrix $^{\mathrm{TM}}$}

PuraMatrix $^{\mathrm{TM}}$ is a synthetic peptide of 16 amino acids which forms a regular, transparent hydrogel when exposed to salt-containing solutions, such as growth media. Undiluted, it is $1 \%$ $(\mathrm{w} / \mathrm{v})$ of protein to water. Similar to Matrigel ${ }^{\mathrm{TM}}$, PuraMatrix ${ }^{\mathrm{TM}}$ is designed to mimic the basement membrane. Although it is synthetic, PuraMatrix ${ }^{\mathrm{TM}}$ has been shown to be biocompatible with a variety of cells (www.bdbiosciences.com). PuraMatrix ${ }^{\mathrm{TM}}$ has a low $\mathrm{pH}$ of approximately 2.4. To form a gel, the PuraMatrix ${ }^{\mathrm{TM}}$ was incubated at $37^{\circ} \mathrm{C}$ for 60 minutes. Twice growth media was added to the PuraMatrix ${ }^{\mathrm{TM}}$ to equilibrate the $\mathrm{pH}$. The undiluted PuraMatrix ${ }^{\mathrm{TM}}$ was dispensed at low pressure and using a $100 \mu \mathrm{m}$ metal tip. When extruded, PuraMatrix ${ }^{\mathrm{TM}}$ Was 
liquid before dropping into the growth media. In growth media, the PuraMatrix ${ }^{\mathrm{TM}}$ formed a loose hydrogel, significantly less stiff than Matrigel ${ }^{\mathrm{TM}}$ or Extracel ${ }^{\circledR}$. The size of the drops formed also spread a great deal. Of concern for later testing is evidence of air bubbles in the hydrogel drops.

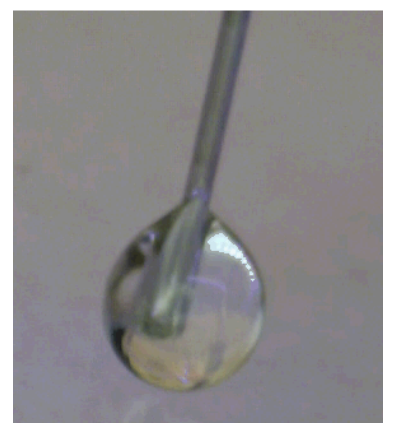

Figure 9: PuraMatrix ${ }^{\mathrm{TM}}$ before extrusion into growth media is a high viscosity liquid.

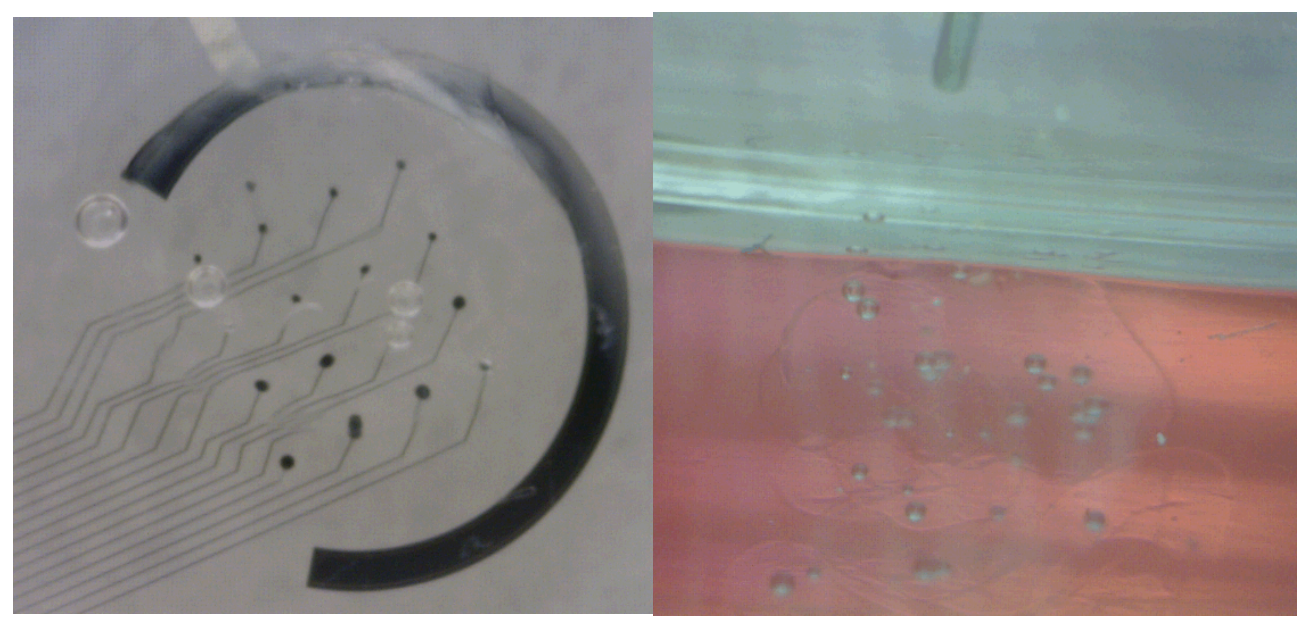

Figure 10: Puramatrix ${ }^{\mathrm{TM}}$ sample in growth media viewed from top (left) and from the side (right).

\section{Collagen}

Two collagen solutions were tested: a bovine Type I collagen and a human type I collagen. Although both appeared to form relatively solid gels after incubation, when printed both became extremely loose and did not hold their shape. The human collagen was particularly loose and became liquefied after extrusion. 


\section{Agarose Bioprinting}

Agarose, a polysaccharide derived from algae, is an inert hydrogel that can be used as a scaffold (Jakab, 9). Bioprinted agarose showed significantly higher stiffness than the natural and synthetic protein-based hydrogels. Agarose solutions were printed at concentrations of $1.0 \%$, $1.5 \%$, and $2.0 \%$. Only $2 \%$ agarose produced a cylinder that maintained its shape. However, bioprinting this agarose required a significantly higher dispensing pressure. For the $2 \%$ agarose gel, which was gelled in the syringe, pressure of 11.0 psi allowed the gel to be dispensed using a $1.19 \mathrm{~mm}$ plastic tip. Unfortunately after dispensing approximately two centimeters of agarose, the remaining agarose was extruded into large, extremely hard clumps of agarose. This may be due to air bubbles as well as the build-up of air pressure within the syringe. Although this applied pressure may be too high for viable cell culturing and tissue development, the shape of the extrusion maintained a smooth cylindrical shape. This inconsistency in texture may limit the utility of using agarose for further bioprinting. Additionally, the agarose would have to either be degraded or combined with other materials to create a three-dimensional environment in which cells would be viable for tissue engineering.

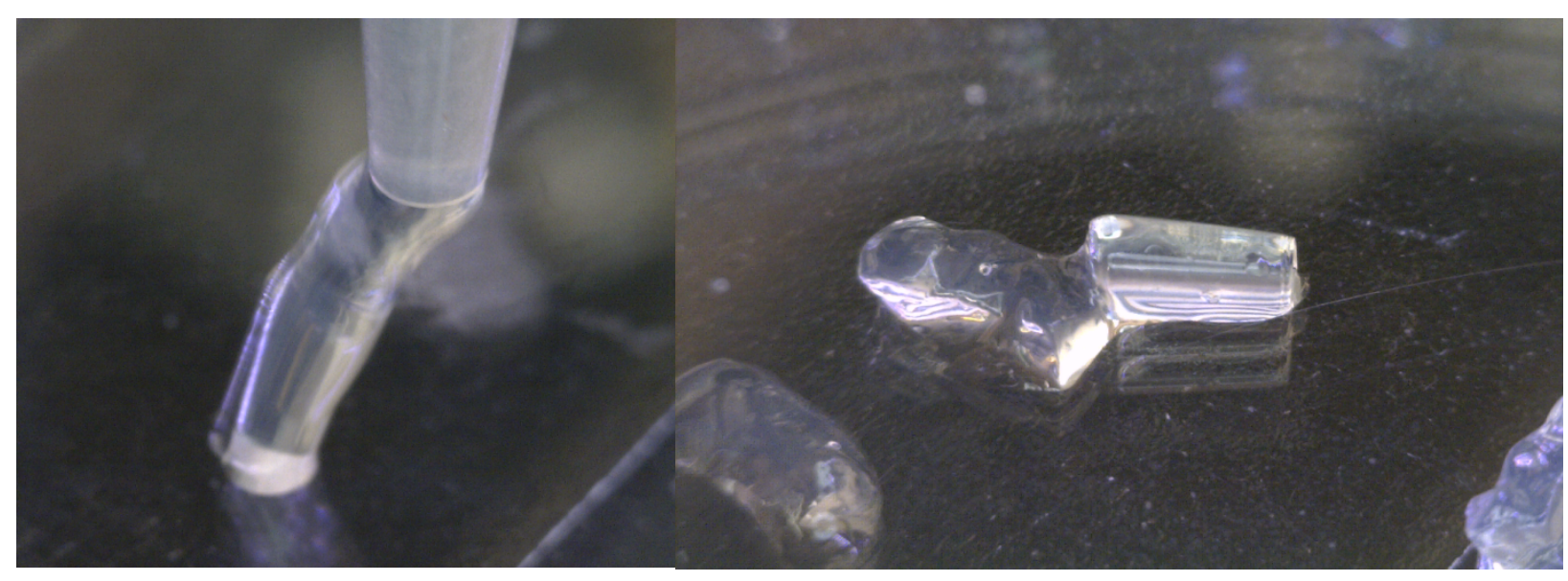

Figure 11: 2\% agarose gel being extruded; cylindrical shape one hour after extrusion. 
Solutions of agarose at $1.0 \%$ and $1.5 \%$ produced very soft gels that did not hold their shape during printing. The extrusions were filled with air bubbles and spurted unevenly from the nozzle at pressures of 10.0 to 15.0 psi. Additionally, these appeared to clog the nozzle after only a short time, further limiting their suitability as a bioink.

\section{Sodium Alginate}

Alginate is a polysaccharide derived from seaweed and has been used in many applications to make hydrogels that can encapsulate cells with good viability results (Jeon, 2724; Kong, 4028). Recently sodium alginate has been used with a calcium chloride cross-linker to create micro-channels by using coaxial, pressure extrusion bioprinting (Zhang, 2). Researchers found that by extruding sodium alginate from one nozzle and calcium chloride from another, a tube could be printed that could support cell growth over many days and permit liquid to be passed through the tube (Id., 7). Sodium alginate gels immediately upon contact with the calcium ions. These experiments used a range of concentrations of the sodium alginate (3\% to $6 \%$ ) and calcium chloride ( $2 \%$ to $5 \%)$ at pressures up to $0.7 \mathrm{psi}$ (Id., $4-5,9)$.

We used our single nozzle bioprinter to create sodium alginate hydrogels crosslinked with calcium chloride. Rather than extrude sodium alginate and calcium chloride separately, we dispensed sodium alginate into a petri dish filled with calcium chloride solution. Two concentrations of sodium alginate were used: $2 \%$ and $4 \%$ dissolved in deionized water. A $4 \%$ calcium chloride solution was used initially, but we also dispensed calcium chloride that was mixed with growth media making a solution of $2 \%$ calcium chloride. The sodium alginate was extruded from a $406 \mu \mathrm{m}$ tip at $2.0 \mathrm{psi}$ of air pressure. Both concentrations of sodium alginate produced solid strings, as well as amorphous clumps, when dispensed into the calcium solution. 
The $4 \%$ sodium alginate appeared to give thicker extrusions, even when dispensed at the same pressure and nozzle diameter than the $2 \%$ sodium alginate. Both had firm but pliable textures.

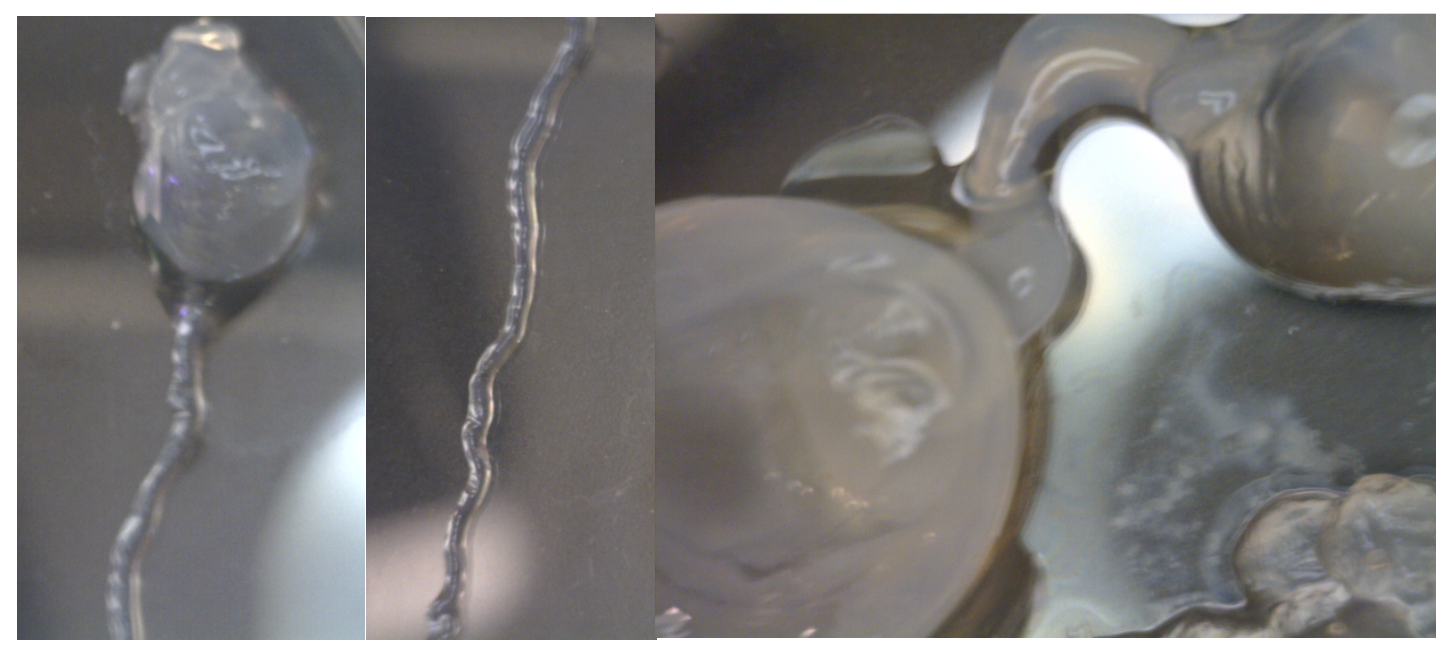

Figure 12: $2 \%$ sodium alginate dispensed into $2 \%$ calcium chloride in water (left); $2 \%$ sodium alginate dispensed into $2 \%$ calcium chloride in 1:1 water/growth media (center); $4 \%$ sodium alginate dispensed into $2 \%$ calcium chloride in 1:1 water/growth media (right).

The sodium alginate structures were placed in a petri dish and covered with growth media, then stored in an incubator at $37{ }^{\circ} \mathrm{C}$ overnight. After 16 hours, both the $2 \%$ and $4 \%$ extrusions maintained their structure and texture. Furthermore, there was a noticeable change in the color from clear to pink, as observed by eye, indicating that the sodium alginate absorbed the surrounding growth media.

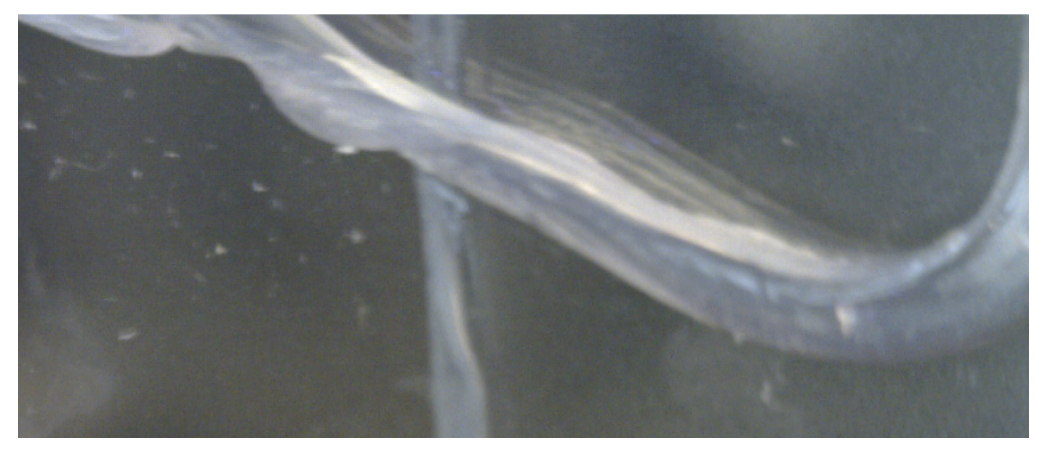

Figure 13: 2\% sodium alginate soaked overnight in growth media. 
In addition to printing with a standard nozzle, a coaxial nozzle was also used to print sodium alginate. Also, this was printed into a tall, thin container several centimeters high, rather than in a flat petri dish. A thin metal rod was placed into a $1.1 \mathrm{~mm}$ plastic nozzle which was used to print the liquid $4 \%$ sodium alginate slowly into $2 \%$ calcium chloride solution. A short pulse of $0.1 \mathrm{psi}$ of air pressures was used allowing the alginate to be extruded very slowly forming a long, thin cylinder. Although the rod was in place, the sample was solid rather than a tube. Lower concentrations of sodium alginate were tested using this method, but only produced amorphous forms rather than cylindrical shapes.

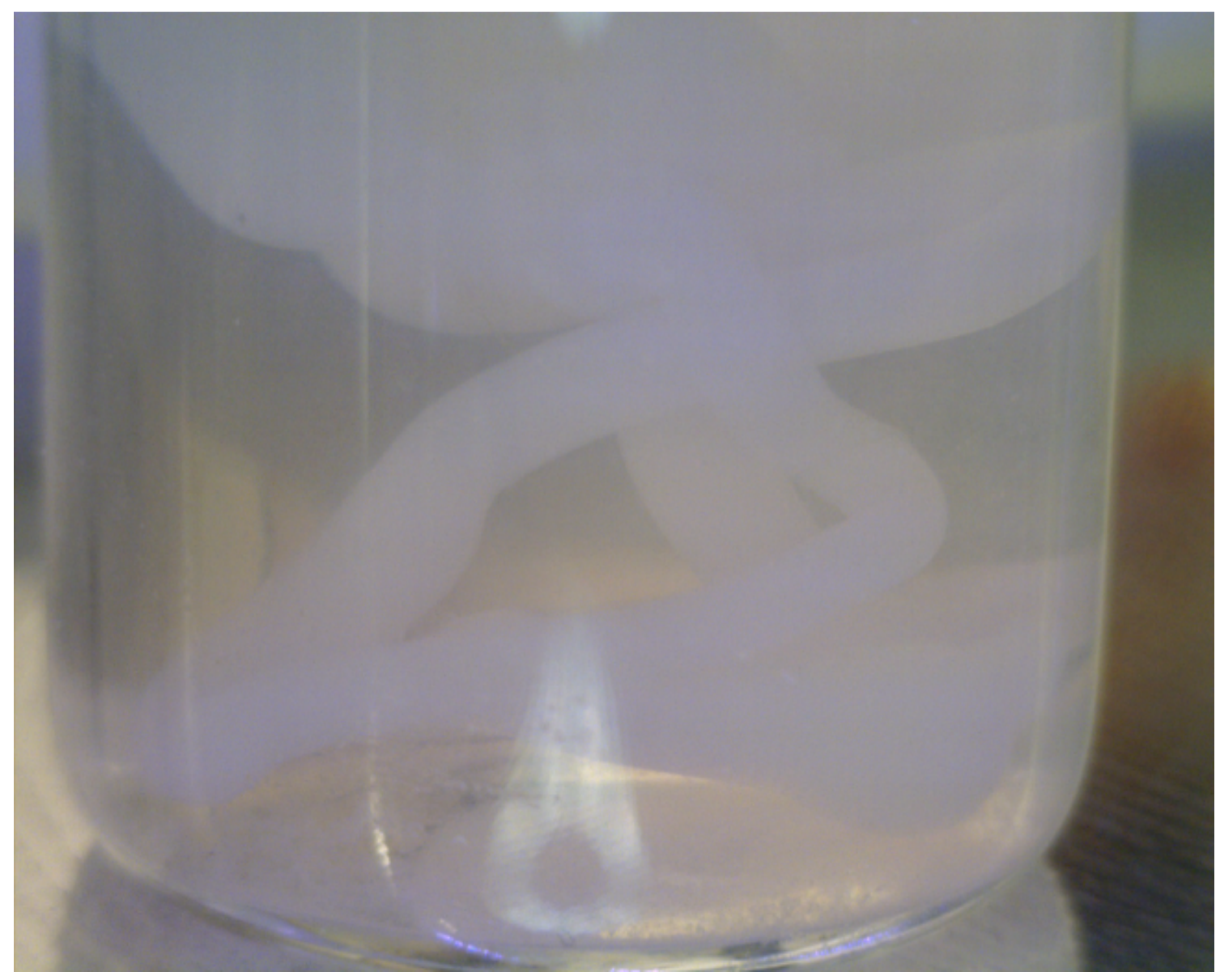

Figure 14: 4\% sodium alginate extruded into a tube of $2 \%$ calcium chloride solution.

\section{Neuron Bioprinting}


Because the bioprinter was successful in delivering extremely precise placement of small volumes of growth media, we tested bioprinting PDL and neurons. PDL is a commonly used net cationic protein that is used to assist anionic cell surfaces, such as that of neurons, to adhere to polystyrene plates or other surfaces. We bioprinted precise drops of PDL onto polyimide-coated coupons, and also flooded the coupons with PDL, to ascertain whether more precise or even PDL distribution would enable neurons to adhere more preferentially to the electrode arrays. The smaller drops show a round shape of printed PDL is maintained; larger drops show spreading due to high viscosity of PDL. After four days, the neurons that were spotted onto the printed PDL were observed and showed good health, as well as preferential attachment to the area where PDL was printed compared to samples that were flooded manually with PDL.

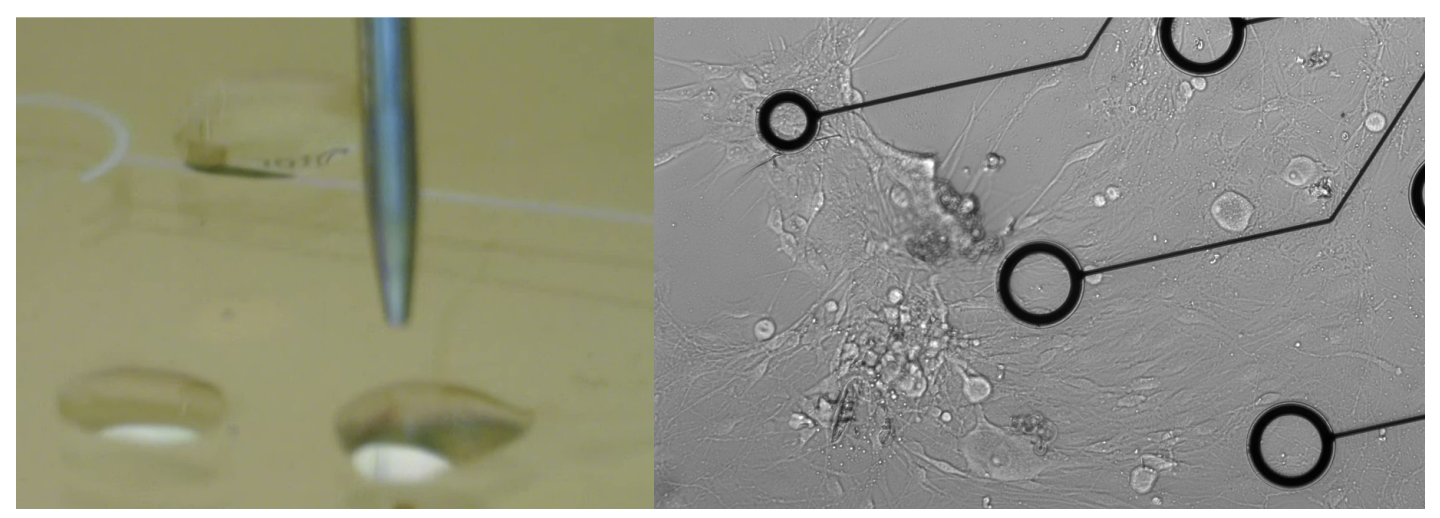

Figure 15: Drops of bioprinted PDL; neurons spotted onto printed PDL drops.

Second, neurons were printed on surfaces previously coated with PDL manually. Large drops appeared to be more successful than smaller arrays, but both were difficult procedures for cell viability. The droplets, particularly in the array format, are of such small volume that they dried within seconds upon extrusion. However, flooding the bioprinted array immediately appears to cause the cells to be washed away from the electrode surface. 

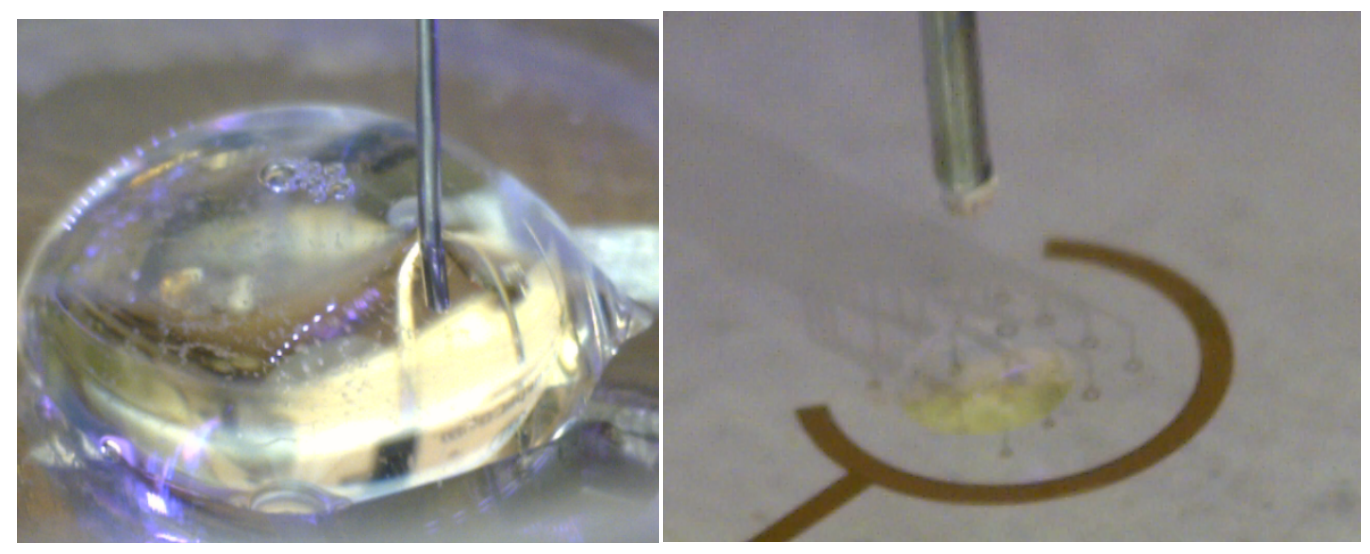

Figure 16: Neurons in growth media being extruded from the bioprinter (left); large drop of neurons over electrode array.

\section{HUVEC Bioprinting}

To begin assessing whether our bioprinting methods would allow cells to maintain their viability, we printed HUVECs in $1 \mathrm{~mL}$ of growth media which was mixed into $1 \mathrm{~mL}$ of $4 \%$ sodium alginate to create a solution of $2 \%$ sodium alginate. This was extruded into a well containing $4 \%$ calcium chloride diluted into an equal amount of growth media for a $2 \%$ calcium chloride solution. The alginate-HUVEC mixture was dispensed by two methods: (1) in very small droplets that only covered the electrode array of a coupon and (2) in large drops that covered a much larger surface area. The cell-alginate mixture was extruded from a $406 \mu \mathrm{m}$ plastic tip at 0.2 psi. Three small droplets were extruded, and eight large drops were extruded. The samples were covered with growth media and incubated overnight. Upon visual observation after 16 hours, no HUVECs were seen in the small droplets. This may have been due to an initial low concentration of HUVECs in the very small droplets. However, many HUVECs were seen in the large drops. As expected, the cells were distinctively encapsulated in the three-dimensional alginate and primarily situated above the electrode array. Only one of the eight samples showed cells within the same field of view as the electrodes, Figure 17. In the other samples, the 
HUVECs were above the electrode array up to several millimeters. Many of the cells appeared to be healthy, although further viability testing was not able to be conducted at the time.

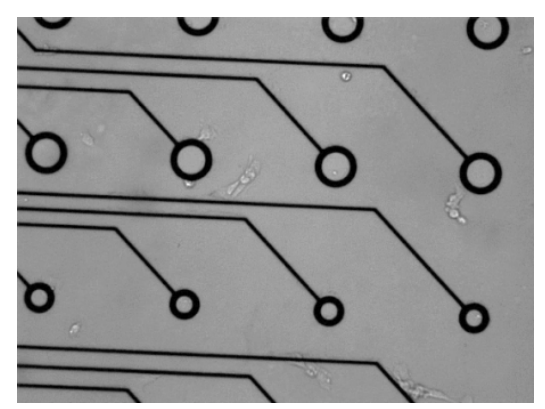

Figure 17: Layer of sodium alginate with HUVECs printed onto polyimide coated coupon. Cells appear in the same plane as the electrodes.

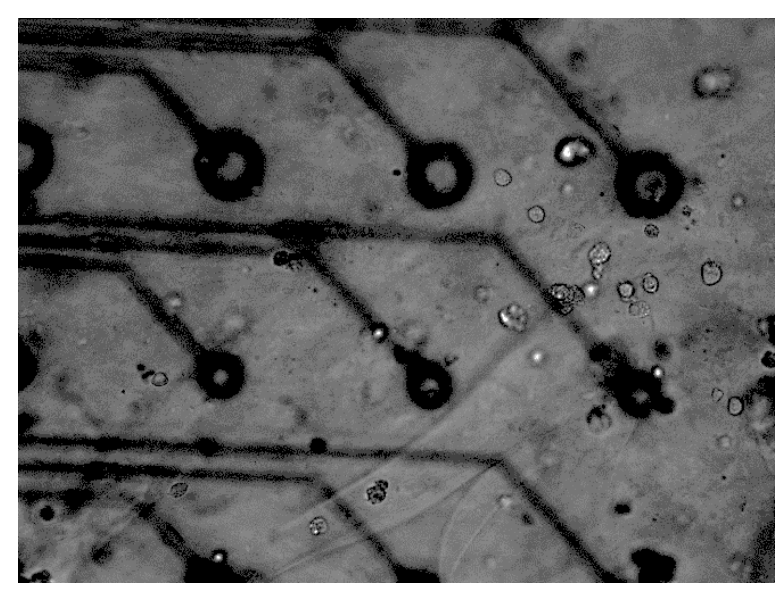

Figure 18: HUVECs in sodium alginate three-dimensional hydrogel. Cells and electrode array cannot be simultaneously in focus, indicating the cells are above the device.

\section{DISCUSSION}

To develop bioprinting of vasculature, several attributes for a potential bioink had to be taken into account. In particular, the bioink must be able to hold a hollow, cylindrical shape after extrusion, but simultaneously cannot be so stiff as to prohibit cell growth or cause tumor-like growth. Many materials proved to be too soft and fragile when extruded and would not be able to hold the form needed to develop into vasculature. Some of these materials, such as Matrigel ${ }^{\mathrm{TM}}$, 
may be useful in combination with stiffer materials, such as sodium alginate, as the natural ECM proteins could help tissue growth in later experiments.

Very stiff/low viscosity materials, such as agarose, tended to clog the nozzle of the bioprinter completely or required very high air pressure to be dispensed (e.g., over $10.0 \mathrm{psi}$ ). Although these materials were not examined for their ability to maintain cell viability, it is expected that shear stress from that pressure would negatively impact the development of tissue in further experimentation. That said, substances that could be extruded at lower pressures and maintain their shape, such as sodium alginate, show promise. Indeed, as the growth factors PDGF and TGF- $\beta$ are secreted under shear stress (Jakab, 10), it is possible that the lower levels of shear stress caused by tubular bioprinting of endothelial cells could positively influence the development of vascularization in tissue engineering.

Testing of bioprinting various arrays with growth media demonstrated that the bioprinter is capable of producing very accurate and precise placement of materials at only $100 \mu \mathrm{m}$ in diameter. With augmentation of the system, even smaller drops may be possible. Moreover, for the creation of more complex models that include multiple cell types, the precision of the bioprinter may allow the exact placement of cells to mimic tissue. For printing onto microelectrode arrays, PuraMatrix ${ }^{\mathrm{TM}}$ and sodium alginate may be optimized.

Finally, the successful printing of HUVECs and neurons demonstrated that the extrusion method of bioprinting using the above methodologies was viable for three-dimensional cell culturing and perhaps tissue engineering.

\section{CONCLUSION AND FUTURE RESEARCH}

The development of a bioink that can sufficiently hold a cylindrical shape is an important step toward developing thicker three-dimensional tissue culture, because this could enable 
samples to have working vasculature networks. The material which appeared most successful from these initial experiments was sodium alginate cross-linked in calcium chloride. However, the most precise printing was done with the highest viscosity material, growth media, which is preferable for direct printing onto electrodes. A combination of these materials may enable precise placement with robust structure. Future research in the area of utilizing bioink to print three-dimensional vascular tissue provides many research opportunities for drug testing, toxicity screening, and regenerative medicine. A next step will be to refine the materials and methods to engineer endothelial cells that will remain viable and form vascular tissue that can deliver nutrients and remove waste via more natural perfusion. If this is successfully done, then other tissue may be engineered with this perfuseable microvasculature. Doing so will enable researchers to understand the physiology of tissues more accurately, test drug delivery, and observe how infectious agents may enter different types of tissues. 


\section{REFERENCES}

Aizawa Y and Shoichet MS, The role of endothelial cells in the retinal stem and progenitor cell niche within a 3D engineered hydrogel matrix, Biomat. 33 (2012) 5198-5205

Arnaoutova I, et al., The endothelial cell tube formation assay on basement membrane turns 20: state of the science and the art, Angiogenesis 12 (2009) 267-74.

Baker B and Chen C, Deconstructing the third dimension - how 3D culture microenvironments alter cellular cues, J. of Cell Sci. 125 (2012) 1-10.

Ballabh P, et al., The blood-brain barrier: an overview Structure, regulation, and clinical implications, Neuro. of Dis. 16 (2004) 1-13

Camci-Unal G, et al., Hydrogel surfaces to promote attachment and spreading of endothelial progenitor cells, J. Tissue Eng. and Regen. Med. 7 (2013) 337-47.

Camejoa G, et al., Association of apo B lipoproteins with arterial proteoglycans: pathological significance and molecular basis, Atherosclerosis 139 (1998) 205-222.

Chen RS, et al., Cell-surface interactions of rat tooth germ cells on various biomaterials, J. Biomed. Mater. Res. A. (2007) 83A(1): 241-8.

Chung S, et al., Cell Migration into scaffolds under co-culture conditions in a microfluidic platform, Lab Chip 9 (2009) 269-75.

Duan B, et al., 3D bioprinting of heterogenous aortic valve conduits with alginate/gelatin hydrogels, J. Biomed. Mater. Res. Part A 101A (2013) 1255-64.

Esch MB, et al., The role of body-on-a-chip devices in drug and toxicity studies, Annu. Rev. Biomed. Eng. 13 (2011) 55-72.

Fiejdasz S, et al., Biopolymer-based hydrogels as injectable materials for tissue scaffold repairs, Biomat. 8 (2013) 035013. 
Fox, GA, Team science successfully identifies 6,000 bugs simultaneously, Sci. \& Tech. Rev., Lawrence Livermore National Laboratory April/May 2013.

Gronkbot 3D Printing, 3D printing basics, posted Apr. 18, 2013, http://gronkwena.wordpress.com/2013/04/18/3d-printer-basics/ (last accessed July 22, 2013).

Guvendiren M and Burdick JA, Stiffening hydrogels to probe short- and long-term cellular responses to dynamic mechanics, Nat. Commun. 3:792 (2012) 792.

Haiguang Z, et al., Fabrication and physical and biological properties of fibrin gel derived from human plasma, Biomed. Mater. 3 (2008) 015001.

Han F, et al., Performance of a multilayered small-diameter vascular scaffold dual-loaded with VEGF and PDGF, Biomat. 34 (2013) 7302-7313.

Han, L-H, et al., Dynamic tissue engineering scaffolds with stimuli-responsive macroporosity formation, Biomat. 34 (2013) 4251-4258.

Jakab K, et al., Tissue engineering by self-assembly and bio-printing of living cells, Biofab. 2 (2010) 022001 1-14.

Jeon $\mathrm{O}$, et al., Photocrosslinked alginate hydrogels with tunable biodegradation rates and mechanical properties, Biomat. 30 (2009) 2724-34.

Kong HJ, et al., Designing alginate hydrogels to maintain viability of immobilized cells, Biomat. 24 (2003) 4023-9.

Kouwer PHJ, et al., Responsive biomimetic networks from polyisocyanopeptide hydrogels, Nature 493 (2013) 651-5.

Lamalice L, et al., Endothelial cell migration during angiogenesis, Migrations of Vascular Cells (2007) 782-93. 
Le Boeuf F, et. al, The Extra Cellular Matrix at a Glance, J. of Cell Sci. 123 (2010) 4195-4200L.

Lodish H, et al. Molecular Cell Biology. 4th ed. New York: W. H. Freeman; 2000.

Nahmias Y, et al., Laser-guided direct writing for three-dimensional tissue engineering, Biotech. and Bioeng. 19:2 (2005) 129-36.

Nikkhah M, et al., Directed endothelial cell morphogenesis in micropatterned gelatin methacrylate hydrogels, Biomat. 22 (2012) 9009-9018.

Norotte C, et al., Scaffold-free vascular tissue engineering using bioprinting, Biomat. 30 (2009) 5910-17.

Ozbolat I and Yu Y, Bioprinting toward organ fabrication: challenges and future trends, Biomed. Eng. 60:3 (2013) 691-9.

PuraMatrix $^{\text {TM }}$ Peptide Hydrogel, BD Biosciences, http://www.bdbiosciences.com/ptProduct.jsp?prodId=554005

Roh J, Tissue-engineered vascular grafts transform into mature blood vessels via an inflammation-mediated process of vascular remodeling, PNAS 107:7 (2010) 4669-74.

Shin Y, et al., Microfluidic assay for simultaneous culture of multiple cell types on surfaces or within hydrogels, Nature Protocols 7:7 (2012) 1247-59.

Tibbitt M and Anseth K, Hydrogels as extracellular matrix mimics for 3D cell culture, Biotech. and Bioeng. 109 (2009) 655-63.

Williams DF, On the mechanisms of biocompability. Biomat. 29 (2008) 2941-53.

Wu MH, et al., Development of perfusion-based micro three-dimensional cell culture platform and its application for high throughput drug testing, Sensors and Actuators B 129 (2008) 231-240. 
Zhang Y, et al., Characterization of printable cellular micro-fluidic channels for tissue engineering, Biofab. 5 (2013) 025004 1-11. 